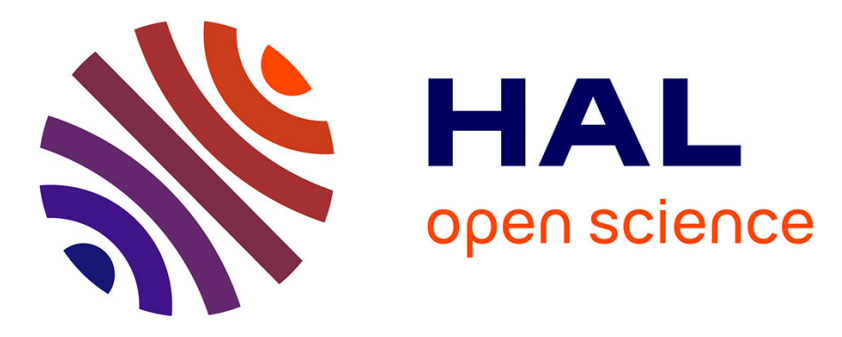

\title{
Linear face-sharing trioctahedral [Mo3I12]3- by spontaneous thf loss from [Mol4(thf)2]-: structure, bonding and magnetic properties
}

James Fettinger, Sundeep Mattamana, Charles O'Connor, Rinaldo Poli, Ghadi Salem

\section{To cite this version:}

James Fettinger, Sundeep Mattamana, Charles O'Connor, Rinaldo Poli, Ghadi Salem. Linear facesharing trioctahedral [Mo3I12]3- by spontaneous thf loss from [Mol4(thf)2]-: structure, bonding and magnetic properties. Journal of the Chemical Society, Chemical Communications, 1995, 12, pp.12651266. 10.1039/C39950001265 . hal-03531199

\author{
HAL Id: hal-03531199 \\ https://hal.science/hal-03531199
}

Submitted on 18 Jan 2022

HAL is a multi-disciplinary open access archive for the deposit and dissemination of scientific research documents, whether they are published or not. The documents may come from teaching and research institutions in France or abroad, or from public or private research centers.
L'archive ouverte pluridisciplinaire HAL, est destinée au dépôt et à la diffusion de documents scientifiques de niveau recherche, publiés ou non, émanant des établissements d'enseignement et de recherche français ou étrangers, des laboratoires publics ou privés. 


\title{
Linear Face-sharing Trioctahedral $\left[\mathrm{Mo}_{3} \mathrm{I}_{12}\right]^{3-}$ by Spontaneous thf Loss from $\left[\mathrm{Mol}_{4}(\mathrm{thf})_{2}\right]^{-}:$: Structure, Bonding and Magnetic Properties
}

\author{
James C. Fettinger, ${ }^{a}$ Sundeep P. Mattamana, ${ }^{a}$ Charles J. O'Connor, ${ }^{b}$ Rinaldo Poli*a and Ghadi Salem ${ }^{a}$ \\ a Department of Chemistry and Biochemistry, University of Maryland, College Park, Maryland 20742, USA \\ b Department of Chemistry, University of New Orleans, New Orleans, Louisiana 70148, USA
}

Complexes $\left[\mathrm{Mo}_{3} \mathrm{X}_{12}\right]^{3-}(\mathrm{X}=\mathrm{I}, \mathrm{Br})$ assemble by spontaneous thf loss in noncoordinating solvents from [MoX $\left.\mathrm{M}_{4}(\text { thf })_{2}\right]^{-}$ and exhibit a linear face-shared trioctahedral structure with, at the same time, delocalized metal-metal bonding and local moment antiferromagnetic exchange interactions.

Halide complexes of molybdenum(III) adopt an octahedral coordination geometry, as in mononuclear $\left[\mathrm{MoX}_{6}\right]^{3-1}$ and dinuclear face-shared bioctahedral $\left[\mathrm{Mo}_{2} \mathrm{X}_{9}\right]^{3-2}{ }^{1}$ The structure of $\mathrm{MoX}_{3}(\mathrm{X}=$ halogen $)$ consists of close-packed $\mathrm{X}$ atoms with the Mo centres filling one-third of the octahedral holes, in such a way that metal-metal bonded face-shared $\mathrm{Mo}_{2} \mathrm{X}_{9}$ bioctahedra are present. ${ }^{2,3}$ For instance, the structure of $\mathrm{MoBr}_{3} 3$ consists of one-dimensional $(\mu-\mathrm{Br})_{3} \mathrm{Mo}(\mu-\mathrm{Br})_{3}$ stacks with alternating MoMo bonding and nonbonding contacts. ${ }^{3}$ The ions 1 and 2 can be thought of as fragments of the extended structure 3. The only reported larger fragment of this structure is $\left[\mathrm{Mo}_{3} \mathrm{Cl}_{12}\right]^{3-}$, which was obtained from the thermal condensation of $\left[\mathrm{Mo}_{2} \mathrm{Cl}_{9}\right]^{2-}$ and $\left[\mathrm{MoCl}_{3}(\mathrm{CO})_{4}\right]^{-}$, but was not investigated crystallographically, nor was its electronic structure described. ${ }^{4}$ Here we report the preparation, by a novel synthetic method, and preliminary studies of the $\left[\mathrm{Mo}_{3} \mathrm{X}_{12}\right]^{3-}(\mathrm{X}=\mathrm{Br}, \mathrm{I})$ ions, and the structural characterization of the iodide complex which reveals, contrary to 3 , delocalized metal-metal bonding.

A number of new trans- $\left[\mathrm{MoX}_{4}(\text { thf })_{2}\right]^{-}$salts $(\mathrm{X}=\mathrm{Br}, \mathrm{I})$ have been isolated from the reaction of $\mathrm{MoX}_{3}(\mathrm{thf})_{3}$ and the desired salt of $\mathrm{X}^{-}$in thf. $\dagger$ The analogous formation of trans$\left[\mathrm{MoCl}_{4}(\text { thf })_{2}\right]^{-}$from $\mathrm{MoCl}_{3}(\text { thf })_{3}$ and $\mathrm{Cl}^{-}$has been previously reported. ${ }^{5,6}$ These compounds are stable in the solid state and in thf, but dissolution in dichloromethane or chloroform results in a smooth and quantitative loss of the thf ligands, as established by ${ }^{1} \mathrm{H}$ NMR integration of free thf against the internal reference of the diamagnetic cation resonances [eqn. (1)]. Salts of the $\left[\mathrm{Mo}_{3} \mathrm{X}_{12}\right]^{3-}$ anions have been isolated either by this procedure or by carrying out the reaction between $\mathrm{MoX}_{3}(\text { thf })_{3}$ and $\mathrm{X}^{-}$ directly in $\mathrm{CH}_{2} \mathrm{Cl}_{2} \ddagger$

$3\left[\mathrm{MoX}_{4}(\text { thf })_{2}\right]^{-} \stackrel{\mathrm{CH}_{2} \mathrm{Cl}_{2}}{\longrightarrow}\left[\mathrm{Mo}_{3} \mathrm{X}_{12}\right]^{3-}+6$ thf $(\mathrm{X}=\mathrm{Br}, \mathrm{I})$

The corresponding $\left[\mathrm{Mo}_{3} \mathrm{Cl}_{12}\right]^{3-}$ species cannot be obtained by this method, as only 1.5 thf moles per mole of $\left[\mathrm{MoCl}_{4}(\mathrm{thf})_{2}\right]^{-}$are released, presumably to give a $\left[\mathrm{Mo}_{2} \mathrm{Cl}_{8} \text { (thf) }\right]^{2-}$ product, a related phosphine derivative of which, $\left.\left[\mathrm{Mo}_{2} \mathrm{Cl}_{8} \mathrm{PEt}_{3}\right)\right]^{2-}$, has been recently described. ${ }^{7}$ This process of thf replacement by a bridging halide is reminiscent of, but proceeds further with respect to, the thf loss from $\mathrm{MoX}_{3}(\mathrm{thf})_{3}$ in non-coordinating solvents to afford edge-sharing bioctahedral $\mathrm{Mo}_{2} \mathrm{X}_{6}(\text { thf })_{4}$ and ultimately face-sharing bioctahedral $\mathrm{Mo}_{2} \mathrm{X}_{6}$ (thf $)_{3}(\mathrm{X}=\mathrm{Cl}, \mathrm{Br}) .^{8}$

The structure of $\left[\mathrm{PPh}_{4}\right]_{3}\left[\mathrm{Mo}_{3} \mathrm{I}_{12}\right]$ has been determined by Xray crystallography. $\S$ The $\left[\mathrm{Mo}_{3} \mathrm{I}_{12}\right]^{3-}$ trianion (Fig. 1) clearly shows a linear face-sharing trioctahedral geometry. The only

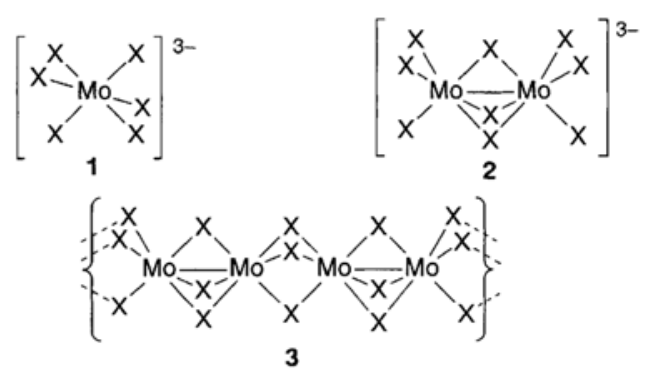

other structurally characterized dodecahalotrimetal complex ${ }^{9}$ is $\left[\mathrm{Ru}_{3} \mathrm{Cl}_{12}\right]^{4-}$; a few related phosphine derivatives of types $\left[\mathrm{Ru}_{3} \mathrm{Cl}_{8}\left(\mathrm{PR}_{3}\right)_{4}\right]^{n+}(n=0,1)$ and $\left[\mathrm{Ru}_{3} \mathrm{Cl}_{6}\left(\mathrm{PR}_{3}\right)_{6}\right]^{+}$have also been reported. ${ }^{10-12}$ The central metal atom resides on a crystallographic inversion centre. The coordination geometry around each metal atom is very little distorted from ideal octahedral, all cis I-Mo-I angles being in the narrow range 88.4-91.4․

As detailed in the classical contribution of Cotton and Ucko, ${ }^{13}$ an ideal face-sharing bioctahedron is characterized by a $\mathrm{M}-(\mu-\mathrm{X})-\mathrm{M}$ angle of $70.53^{\circ}$. When a metal-metal bonding interaction is not present, a much larger angle results as a consequence of the repulsive interaction (angles greater than $80^{\circ}$ are typically found for molecules having no metal-metal bond). ${ }^{13}$ The average Mo-I-Mo angle of $71.34(7)^{\circ}$ in the $\left[\mathrm{Mo}_{3} \mathrm{I}_{12}\right]^{3-}$ ion thus indicates that metal-metal interactions are present. This angle is smaller than those reported for the trioctahedral metal-metal bonded ruthenium complexes $\left[\mathrm{Ru}_{3} \mathrm{Cl}_{12}\right]^{4-},\left[\mathrm{Ru}_{3} \mathrm{Cl}_{8}\left(\mathrm{PR}_{3}\right)_{4}\right]^{n+}(n=0,1)$ and $\left[\mathrm{Ru}_{3} \mathrm{Cl}_{6}\left(\mathrm{PR}_{3}\right)_{6}\right]^{+}$ (in the range $72-75^{\circ}$ ). ${ }^{9-12}$ The presence of a metal-metal interaction is also consistent with theoretical analyses of this structural type. The results of our calculations at the extended Huckel level (Fig. 2) match those previously reported for $\left[\mathrm{Ru}_{3} \mathrm{Cl}_{12}\right]^{4-} .{ }^{14}$ Whereas two of the three pseudo- $\mathrm{t}_{2 \mathrm{~g}}$ orbitals per Mo atom (of $\pi / \delta$ symmetry with respect to the Mo-Mo-Mo axis) lead to minimal overlap and remain substantially localized on the respective metal centres, the third orbital (of $\sigma$ symmetry) allows the formation of a bonding combination $\left(a_{1 g}\right)$, whose occupation leads to delocalized metal-metal bonding (bond order $1 / 2$ per Mo-Mo bond). Indeed, the Mo-Mo distance in this trinuclear ion $[3.258(2) \AA]$ is only slightly longer than the corresponding distances found in the isoelectonic face-sharing bioctahedral $\left[\mathrm{Mo}_{2} \mathrm{I}_{9}\right]^{3-} \quad[\mathrm{Mo}-\mathrm{Mo}, 3.07(2) \AA]^{15}$ and $\left[\mathrm{Mo}_{2} \mathrm{I}_{7}\left(\mathrm{PMe}_{3}\right)_{2}\right]^{-}[3.022(1) \AA]^{16}$ where the Mo-Mo bond order is 1 . The other seven electrons occupy the central manifold of non-bonding orbitals $\left(2 e_{g}+e_{u}+a_{2 u}\right)$, whereas this manifold is completely filled up in $\left[\mathrm{Ru}_{3} \mathrm{Cl}_{12}\right]^{4-}$.

According to our calculations, the ground state configuration is $\left(e_{g}\right)^{4}\left(e_{u}\right)^{3}$, corresponding to a spin doublet state, but other states with a greater number of unpaired electrons should be close in energy. Indeed, variable temperature magnetic suscep-

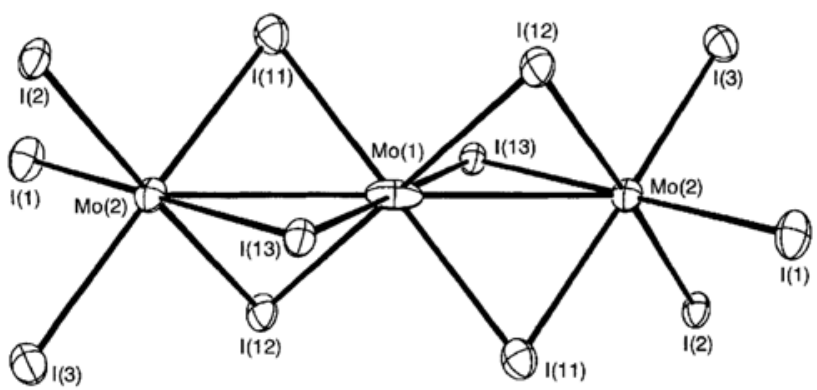

Fig. 1 An ORTEP view of the $\left[\mathrm{Mo}_{3} \mathrm{I}_{12}\right]^{3-}$ ion. Selected distances $(\AA)$ and angles $\left({ }^{\circ}\right)$ (averaged over chemically equivalent parameters; $b=$ bridging, $\mathrm{t}=$ terminal): Mo-Mo 3.258(2), Mo(1) $-\mathrm{I}_{\mathrm{b}} 2.769(10), \operatorname{Mo}(2)-\mathrm{I}_{\mathrm{b}} 2.817(8)$, $\operatorname{Mo}(2)-I_{t} 2.752(4), I_{t}-\operatorname{Mo}(2)-I_{t} 90.4(2), I_{b}-\operatorname{Mo}(2)-I_{b} 88.4(5) I_{b}-\operatorname{Mo}(1)-I_{b}$ $90.4(2), \mathrm{I}_{\mathrm{b}}-\mathrm{Mo}(1)-\mathrm{I}_{\mathrm{b}}{ }^{\prime} 89.6(2), \operatorname{Mo}(1)-\mathrm{I}_{\mathrm{b}}-\mathrm{Mo}(2) 71.34(7)^{\circ}$. 
tibility measurements for $\left[\mathrm{PPh}_{4}\right]\left[\mathrm{Mo}_{3} \mathrm{I}_{12}\right]$ show a moment reduction upon cooling, converging toward the value expected for one unpaired electron per trinuclear unit at low temperature $\left(3.92 \mu_{\mathrm{B}}\right.$ at $200 \mathrm{~K}, 2.38 \mu_{\mathrm{B}}$ at $\left.1.75 \mathrm{~K}\right)$. For comparison, the magnetic moment of $\left[\mathrm{Bu}_{4}{ }_{4} \mathrm{~N}\right]_{3}\left[\mathrm{Mo}_{3} \mathrm{Cl}_{12}\right]$ was reported as 2.02 $\mu_{\mathrm{B}}$ at $302 \mathrm{~K} .{ }^{4}$ In conclusion, the theoretical analysis rationalizes the experimentally verified co-existence, in $\left[\mathrm{Mo}_{3} \mathrm{I}_{12}\right]^{3-}$, of delocalized metal-metal bonding and local-moment antiferromagnetic exchange coupling. The ideal extension of the $\left[\mathrm{Mo}_{n} \mathrm{X}_{3 n+3}\right]^{3-}$ chain to $n=\infty$ would be expected to develop a half-filled $d_{\sigma}$ band (Fig. 2), and the experimentally observed structure of $\mathrm{MoBr}_{3} 3^{3}$ can be viewed as a Peierls-distorted modification of such ideal structure.

Preliminary investigations of the chemistry of $\left[\mathrm{Mo}_{3} \mathrm{X}_{12}\right]^{3-}$ have been carried out. Standing in dilute solutions at room temperature leads to the slow release of $\mathrm{X}^{-}$in an equilibrium process and affords a new type of trinuclear cluster, $\left[\mathrm{Mo}_{3} \mathrm{X}_{11}\right]^{2-}$. Crystals of $\left[\mathrm{Bu}_{4} \mathrm{~N}\right]_{2}\left[\mathrm{Mo}_{3} \mathrm{I}_{11}\right]$ were slowly grown from $\mathrm{CH}_{2} \mathrm{Cl}_{2}$-heptane, but disorder problems prevented a satisfactory refinement of the structure. However, the geometry of the ion is established as a triangular cluster of molecular $D_{3 h}$ symmetry with strong [av. 2.70(3) $\mathrm{A}$ ] metal-metal interactions, as represented in $\mathbf{4}$.

In conclusion, this work has shown: (i) a new strategy for the synthesis of linear face-sharing $\mathrm{Mo}^{\mathrm{III}}$ trioctahedra and the first report of the bromide and iodide members of this class; (ii) the first structural characterization for these trinuclear Mo species, showing the presence of a metal-metal interaction in agreement

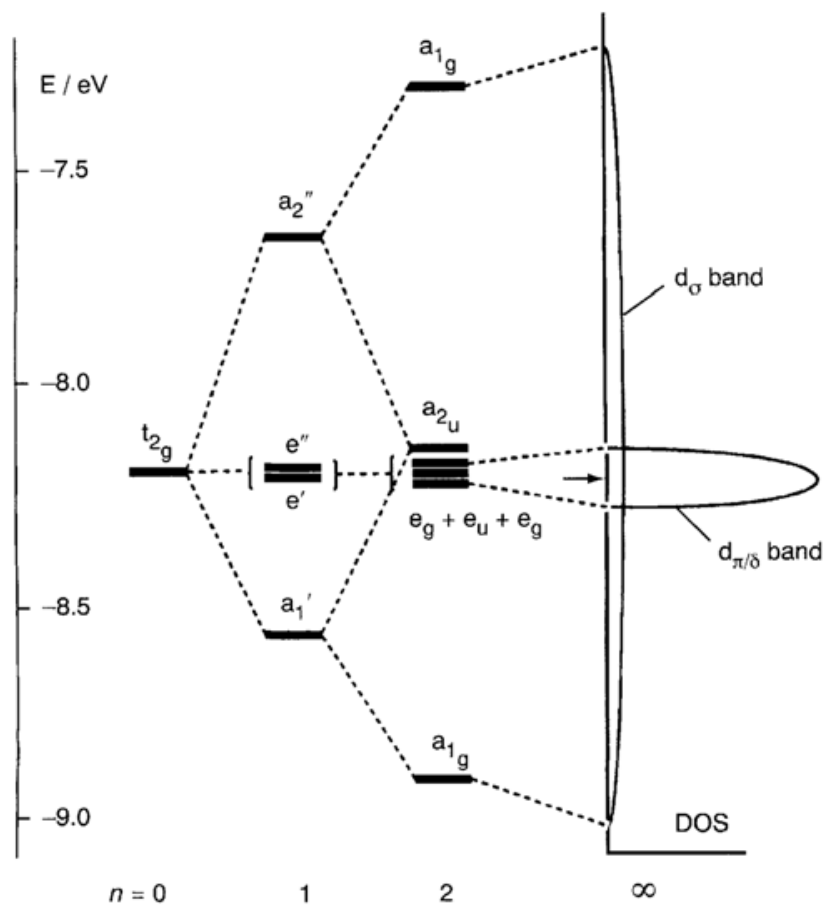

Fig. $2 \mathrm{MO}$ diagram of the metal orbital region for complexes $\left[\mathrm{I}_{3} \mid \mathrm{Mo}(u\right.$ I) $\left.{ }_{3}{ }_{n} \mathrm{MoI}_{3}\right]^{3-}$ (calculated for $n=0,1,2$; qualitative for $\left.n=\infty\right)$. The arrow indicates the Fermi level. with the theoretical prediction of bonds of order 0.5 ; (iii) the magnetic properties of these complexes, again consistent with the theoretical model for the electronic structure.

This research was supported by the National Science Foundation (PYI Award 1990-95). Additional support from the Alfred P. Sloan Foundation in the form of a Research Fellowship (1992-94) is also gratefully acknowledged. We wish to thank Professor Gregory A. Brewer for a preliminary magnetic measurement on $\left[\mathrm{PPh}_{4}\right]\left[\mathrm{Mo}_{3} \mathrm{I}_{12}\right]$.

Received, 4th April 1995; Com. 5/02150B

\section{Footnotes}

† Stirring equimolar mixtures of $\mathrm{MoX}_{3}(\text { thf })_{3}$ and the desired [Cat] $\mathrm{X}\{\mathrm{X}=$ $\mathrm{Br}$, Cat $=\mathrm{Bu}_{4}{ }_{4} \mathrm{~N}, \mathrm{PPN}\left[\left(\mathrm{Ph}_{3} \mathrm{P}\right)_{2} \mathrm{~N}\right] ; \mathrm{X}=\mathrm{I}$, Cat $=\mathrm{PPh}_{4}, \mathrm{Pr}^{\mathrm{n}}{ }_{4} \mathrm{~N}, \mathrm{Bu}^{\mathrm{n}}{ }_{4} \mathrm{~N}$, $\mathrm{PPN}\}$ in thf at room temp. overnight yielded the products, which were filtered, washed and dried under vacuum $(50-80 \%)$. As a representative example, $582 \mathrm{mg}(73 \%)$ of $\left[\mathrm{PPh}_{4}\right]\left[\mathrm{MoI}_{4}(\mathrm{thf})_{2}\right]$ where obtained from $\mathrm{MoI}_{3}$ (thf) $)_{3}(507 \mathrm{mg}, 0.73 \mathrm{mmol})$ and $\mathrm{PPh}_{4} \mathrm{I}(341 \mathrm{mg}, 0.73 \mathrm{mmol})$ in $20 \mathrm{~cm}^{3}$ of thf. Satisfactory $\mathrm{C}, \mathrm{H}$ analyses were obtained for all compounds. Paramagnetically shifted ${ }^{1} \mathrm{H}$ NMR resonances are observed for the coordinated thf ligands $\left(\mathrm{CDCl}_{3}\right.$, room temp. $):\left[\mathrm{MoI}_{4}(\text { thf })_{2}\right]^{-} \delta 100\left(w_{1 / 2}=\right.$ $840 \mathrm{~Hz}, \alpha-\mathrm{H}), 12.5\left(w_{1 / 2}=150 \mathrm{~Hz}, \beta-\mathrm{H}\right) ;\left[\operatorname{MoBr}_{4}(\mathrm{thf})_{2}\right]^{-} \delta 83\left(w_{1 / 2}=\right.$ $1100 \mathrm{~Hz}, \alpha-\mathrm{H}), 9.0\left(w_{1 / 2}=220 \mathrm{~Hz}, \beta-\mathrm{H}\right)$. However, prolonged standing of these solution led to loss of coordinated thf and formation of the $\left[\mathrm{Mo}_{3} \mathrm{X}_{12}\right]^{3-}$ salts, see text.

$\leftarrow$ Depending on the nature of $X$ and the cation, the product either precipitated directly, or was recovered by addition of a nonsolvent (toluene, heptane or diethyl ether) or by cooling to low temperature. Satisfactory C, $\mathrm{H}$ analyses were obtained for all compounds $(\mathrm{X}=\mathrm{Br}$, Cat $=\mathrm{PPN} ; \mathrm{X}=\mathrm{I}$, Cat $\left.=\mathrm{PPh}_{4}, \mathrm{Pr}^{\mathrm{n}}{ }_{4} \mathrm{~N}, \mathrm{Bu}_{4}{ }_{4} \mathrm{~N}, \mathrm{PPN}\right)$. A single crystal of $\left[\mathrm{PPh}_{4}\right]_{3}\left[\mathrm{Mo}_{3} \mathrm{I}_{12}\right]$ suitable for the X-ray analysis was grown by dissolving $\left[\mathrm{PPh}_{4}\right]\left[\mathrm{MoI}_{4}(\text { thf })_{2}\right]$ (230 mg, $0.21 \mathrm{mmol})$ and $\mathrm{PPh}_{4} \mathrm{I}(105 \mathrm{mg}, 0.22 \mathrm{mmol})$ in $\mathrm{CH}_{2} \mathrm{Cl}_{2}\left(5 \mathrm{~cm}^{3}\right)$ and carefully layering the resulting solution with diethyl ether $\left(5 \mathrm{~cm}^{3}\right)$. The solvent diffusion was allowed to occur at $-20^{\circ} \mathrm{C}$.

$\$$ Crystal data for $\left[\mathrm{PPh}_{4}\right]_{3}\left[\mathrm{Mo}_{3} \mathrm{I}_{12}\right] \cdot 1.5\left(\mathrm{CH}_{2} \mathrm{Cl}_{2}\right) \cdot 0.5\left(\mathrm{Et}_{2} \mathrm{O}\right)$ : triclinic, space group $P \overline{\mathrm{I}}, a=11.385(2), b=12.697(3), c=16.849(2) \AA, \alpha=76.65(2)$, $\beta=71.967(12), \gamma=84.56(2)^{\circ}, V=2252.5(7) \AA^{3}, Z=1, D_{c}=2.201$ $\mathrm{Mg} \mathrm{m}^{-3}, \mu(\mathrm{Mo}-\mathrm{K} \alpha)=4.703 \mathrm{~mm}^{-1}, 2 \theta(\max )=45.0^{\circ}$, scan mode $=\omega, \lambda$ $=0.71073 \AA, T=153 \mathrm{~K}, R=0.0574, R_{\mathrm{w}}=0.1236$ for 431 parameters and 3957 data with $I>2 \sigma(I)(6177$ measured reflections, of which 5871 independent, $R_{\mathrm{int}}=0.065$ ). Atomic coordinates, bond lengths and angles, and thermal parameters have been deposited at the Cambridge Crystallographic Data Centre. See Information for Authors, Issue No. 1.

\section{References}

1 Comprehensive Coordination Chemistry, ed. G. Wilkinson, R. D. Gillard and J. A. McCleverty, Pergamon, Oxford, 1988, vol. 3.

2 H. Schäfer, H.-G. von Schnering, J. Tillack, F. Kuhnen, H. Wöhrle and H. Z. Baumann, Z. Anorg. Allg. Chem., 1967, 353, 281.

3 D. Babel, J. Solid State Chem., 1972, 4, 410.

4 W. H. Delphin, R. A. D. Wentworth and M. S. Matson, Inorg. Chem., $1974,13,2552$

5 R. Poli and J. C. Gordon, Inorg. Chem., 1991, 30, 4550.

6 A. Hills, G. J. Leigh, J. Hutchinson and J. A. Zubieta, J. Chem. Soc. Dalton Trans., 1985, 1069.

7 K. Vidyasagar, Inorg. Chim. Acta, 1995, 229, 473.

8 R. Poli and H. D. Mui, J. Am. Chem. Soc., 1990, 112, 2446.

9 A. Bino and F. A. Cotton, J. Am. Chem. Soc., 1980, 102, 608.

10 F. A. Cotton, M. Matusz and R. C. Torralba, Inorg. Chem., 1989, 28 , 1516.

11 F. A. Cotton and R. C. Torralba, Inorg. Chem., 1991, 30, 3293.

12 F. A. Cotton and R. C. Torralba, Inorg. Chem., 1991, 30, 4386.

13 F. A. Cotton and D. A. Ucko, Inorg. Chim. Acta, 1972, 6, 161.

14 B. E. Bursten, F. A. Cotton and A. Fang, Inorg. Chem., 1983, 22, 2127.

15 R. Stranger, I. E. Grey, I. C. Madsen and P. W. Smith, J. Solid State Chem., 1987, 69, 162

16 F. A. Cotton and R. Poli, Inorg. Chem., 1987, 26, 3310. 